\title{
Functional Approaches to Study Leaf Senescence in Sunflower
}

\author{
Paula Fernandez, Sebastián Moschen, Norma Paniego and Ruth A. Heinz \\ Biotechnology Institute - CICVyA-INTA Castelar \\ Argentina
}

\section{Introduction}

Senescence is an age-dependent process at the cellular, tissue, organ or organism level, leading to death at the end of the life span (Noodén 1988). Annual plants as grain and oil crops undergo a visual process towards the end of the reproductive stage that is accompanied by nutrient remobilization from leaf to developing seeds (Buchanan-Wollaston et al. 2003). The final stage of this process is leaf death but this is actively delayed until all nutrients have been removed and recycle through the process of developmental senescence. It have been documented that a delay in leaf senescence has an important impact on grain yield trough the maintenance of the photosynthetic leaf area during the reproductive stage in different crops (Ewing \& Claverie 2000), including sunflower (Sadras et al. 2000; De la Vega et al. 2011). The potential yields of sunflower crop are far from the real ones in all Argentina productive regions. In Balcarce, for example, while the potential yields are estimated in 5,000 kg.ha-1, those obtained by the best producers only reach 3,000 kg.ha-1, and the average in the region ranges in 1,800 kg.ha-1 (Dosio \& Aguirrezábal 2004). These differences could possibly be due to the inability of current hybrids to keep their green leaf area for long periods, which would allow greater use of the incident radiation during the grain filling period which plays an important role in determining the yield and oil concentration in sunflower (Dosio et al. 2000; Aguirrezábal et al. 2003).

Besides autonomous (internal) factors as age, reproductive stage and phytohormone levels, leaf senescence is hardly affected by environmental factors. Among these environmental factors, including extreme temperature, drought, shading, nutrient deficient and pathogen infection, the most limiting ones are water and nutrient availability (Gan \& Amasino 1997; Sadras et al. 2000; Sadras et al. 2000; Dosio et al. 2003; Lim et al. 2003; Aguera et al. 2010).

During leaf senescence, critical and dramatic changes occurred in a highly regulated manner following a genetically programmed process of high complexity. Chlorophyll degradation, nutrient recycling and remobilization are preceded or paralleled by RNA and protein degradation. Even though leaf senescence has been widely recognized and accepted as a type of Programmed Cell Death (PCD) (Noodén \& Leopold 1987), the onset and progression of senescence is accompanied by global changes in gene expression. Thus, deep extensive efforts have been achieved to reveal relevant molecular process by identifying and analysing 
Senescence Associated Genes (SAGs) as prior tags to disclosure the core of this complex process (Kim et al. 2007). SAGs genes have been extensively studied in model plant species (Audic \& Claverie 1997; Gepstein et al. 2003; Balazadeh et al. 2008; Hu et al. 2010) and in some agronomical relevant crops (Andersen et al. 2004; Conesa et al. 2005; Espinoza et al. 2007). Yet, although senescence and ageing might be considered synonyms, a distinct reference was previously discussed because the former comprises all those degenerative changes and cellular degradation occurring with little or non-reference to death, whereas the latter is considered the final developmental stage culminating in death (Nooden \& Leopold 1988; Shahri 2011). In the last year, considering this limitation, many efforts are being achieved to disclosure and obtain genomic information for this oil crop (Kane et al. 2011) but complete sequence information are still no available.

Sunflower (Helianthus annuus L.) is one of the most relevant crops as source of edible oil and many efforts have been achieved to build up useful functional genomics tools for cultivated sunflower involving transcriptional and metabolic profiles (Fernandez et al. 2003; Cabello et al. 2006; Paniego et al. 2007; Fernandez et al. 2008; Peluffo et al. 2010). Although, molecular studies focused on the onset of the senescence process in sunflower leaf are scarce (Fernandez et al. 2003; Dezar et al. 2005; Manavella et al. 2006; Jobit et al. 2007; Paniego et al. 2007; Fernandez et al. 2008; Manavella et al. 2008; Peluffo et al. 2010; Fernandez et al. 2011). Thus, two different approaches are envisage for studying molecular events occurring during leaf senescence: the first strategy relays on the identification of sunflower SAGs based on a candidate gene approach while the second approach involves concerted gene expression studies based on high density oligonucleotide microarrays, whole transcriptome shotgun sequencing and microRNA detection by RNA-seq (Buermans et al. 2010; Dhahbi et al. 2011).

Leaf senescence is a complex and highly coordinated process (Noodén et al. 1997). Although symptoms have been explored, the involved processes and the mechanisms that control it have not been characterized yet (Buchanan-Wollaston et al. 2003). The distinctive symptom of leaf senescence is the breakdown of chloroplasts, therefore the decrease in chlorophyll content becomes a key indicator of the process (Hörtensteiner 2006). Both, the beginning and the rate of senescence may be affected by autonomous and environmental signals.

Environmental factors such as light (Weaver \& Amasino 2001), nutrient availability, concentration of $\mathrm{CO}_{2}$, abiotic and biotic stresses caused by disease (Sadras et al. 2000) may affect the rate of senescence. A previous work (Pic et al. 2002) showed that the sequence of certain events at macroscopic, biochemical and molecular level in pea leaf senescence were not modified in leaves of different age, or under conditions of moderate water stress. Since some of the environmental conditions that affect senescence have important effects on carbon metabolism, previous works assigned to sugar content in leaves an integrating role of environmental signals, regulating leaf senescence (Wingler et al. 2006). Reproductive growth is mentioned as a factor that usually impacts on leaf senescence, and particularly in sunflower, the lack of sinks delays the onset of senescence (Sadras et al. 2000). Control of senescence by growth of reproductive structures was not observed in Arabidopsis thaliana (Noodén \& Penny 2001). Moreover, determining the onset of senescence is complex because there is no a "symptom" indicating this moment. Visual parameters are often used to assess these processes, but both the variation in chlorophyll content and yellowing or necrosis of leaves, are detectable long after the signalling cascade of senescence process is activated. 
Senescence studies are generally based on the accumulation of messenger RNA coding for enzymes involved in degradation of structures, however, this process has a high degree of interaction between endogenous and environmental signals, involving different genes whose expression is induced or inhibited in different stages of the process (Gan \& Amasino 1997). On the other hand, there are relevant studies that inversely correlate senescence with a high level of nitrogen in soil. According to these evidences a high nutritional nitrogen performance along soil profile should lead to a delay leaf senescence in sunflower, avoiding the pronounced symptoms occurred for chlorophyll content (Aguera et al. 2010).

\section{Candidate gene approach to identify SAGs in sunflower}

Senescence Associated Genes (SAGs) refer to genes whose expression level is up-regulated during senescence, in contrast with Senescence Down-regulated Genes (SDGs). These genes could be classified into two classes depending on their expression patterns: Class I genes are those whose expression is only activated during senescence (senescence-specific) whereas class II are those that maintain a basal level of expression during early leaf development, but this level increases when senescence begins (Gan \& Amasino 1997). The expression patterns of these genes may change in response to different conditions of plant growth. Many of these genes can be shared by different regulatory pathways whereas others may belong to a particular pathway. Thus, the inactivation or overexpression of many SAGs may not exhibits significant effect, suggesting a complex regulatory network in leaf senescence process. SAGs can be grouped into several categories based on their predictive function, including macromolecular degradation and recycling, amino acid transport, metabolism, detoxification, regulatory genes, among others (Gepstein et al. 2003).

The main objective in sunflower to open new insights into the early leaf senescence process focuses in the identification and characterization of genetic sequences and metabolic pathways involved in the onset and evolution of the leaf senescence process. This aim involved the analysis of transcriptional and metabolic profiles in leaves from plants growing under different conditions that may alter the senescence rate, concomitant with studies of physiological and biochemical aspects. The specific items involved in this work include:

1. Study of the evolution of leaf area, chlorophyll and sugar content in leaf of different ages in a traditional sunflower hybrid subjected to treatments that alter the senescence under both field and greenhouse conditions.

2. Identification in public sunflower databases of gene sequences orthologous to Senescence Associated Genes (SAG) or Senescence Down-regulated Genes (SDG).

3. Identification of new candidate genes through a sunflower microarray expression analysis.

4. Verification and quantification of the expression profiles of these genes under conditions that accelerate or delay the senescence process.

5. Study of metabolic changes that occurred during the senescence process.

6. Integration of metabolic and transcriptional profile analysis and physiological variables for the detection of useful biomarkers for application in sunflower breeding.

Following a candidate genes strategy, a preliminary assay to detect putative SAGs in sunflower was achieved by selecting few candidates previously described for Arabidopsis thaliana, due to the fact that this was the very first model plant for which a large-scale SAG 
transcriptome was available (Gepstein et al. 2003). For this purpose six candidate SAGs were selected from this plant model (Moschen 2009) to search for orthologous genes in the sunflower EST database using the tblastx algorithm (Altschul et al. 1990), employing bioinformatics tools locally installed and developed. Sequences showing significant similarity parameters were selected and confirmed. Specific oligonucleotides were designed to amplify fragments of approximately $150 \mathrm{bp}$ for further evaluation by quantitative PCR. In a previous study, we have reported the evaluation and identification of a panel of eight reference genes for their application to transcriptional analysis of the leaf senescence process, thus enabling the use of genuine reference genes in ongoing expression studies (Fernandez et al. 2011). Exploratory studies of senescence by qPCR comparing two treatments which affect the rate of leaf senescence were performed: water stress and head excision, relative to a control condition. Samples were taken from two leaves of different ages, leaf 15 and 25 in order to identify functional markers for this process. Two of the selected genes, a gamma vacuolar processing enzyme (AN At5g60360) (D3 gene) involved in the maturation and activation of vacuolar proteins and an aleurain protease AALP, (AN At1g18210) (D4 gene), belonging to the cystein-protease family are classified in the group of macromolecular degradation and recycling; the third gene, a calcium binding protein (AN At4g32940) (R2 gene) belongs to the group of regulatory genes (Gepstein et al. 2003). Furthermore two reference genes were evaluated against these conditions for relative expression studies, Elongation Factor 1-a (AN) and a-Tubuline, selected from a previous study of the performance of different reference genes against these experimental conditions in sunflower (Fernandez et al. 2011). Alfa tubuline (a-Tubuline) showed the most stable behavior; therefore, it was selected as internal control in further analysis of expression of these SAGs (Figure 1).

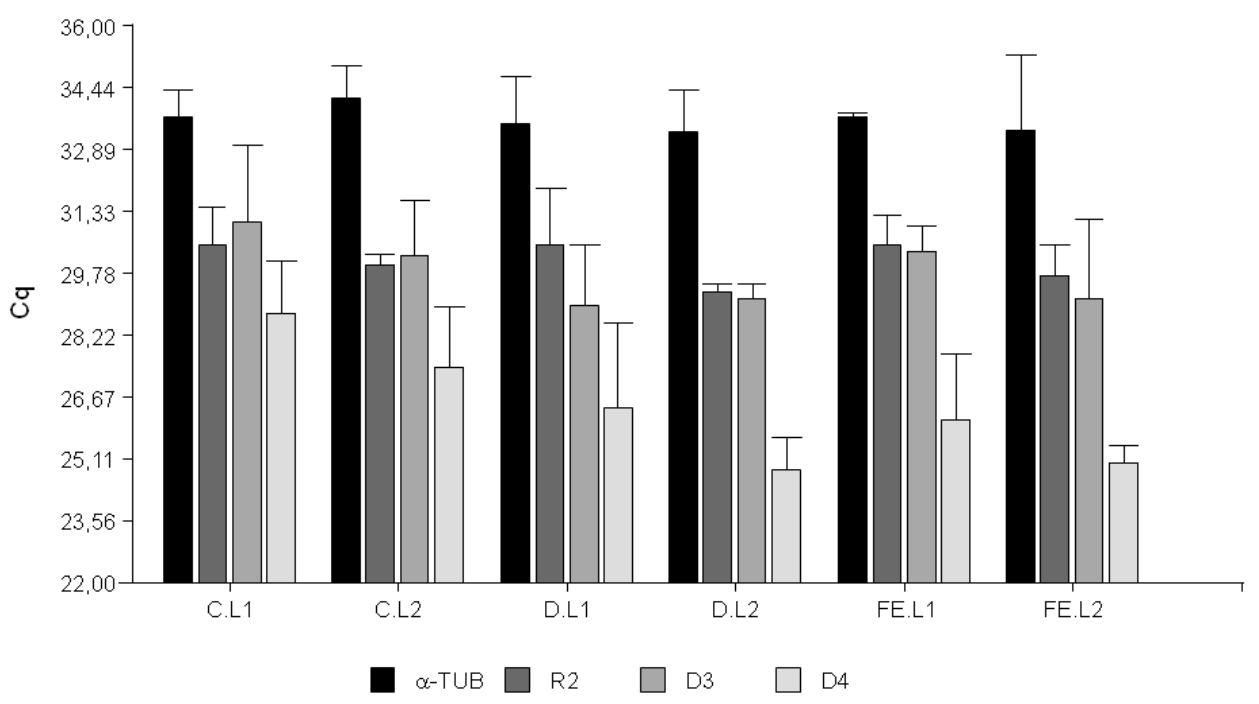

Fig. 1. Average Cq of analyzed SAGs genes normalizing against a-TUB as RG. Error bars show standard deviation (Fernandez et al. 2011). 
The three selected genes did not show significant differences between the evaluated conditions at the sampling times tested (63 days post-emergence) (Table 1). It is worth noting that the target genes showed high expression levels even in controls plants with values close to the water stressed samples. Thus, these genes were probably induced by internal plant factors at an early time point, prior to the tested time in that assay. On the other hand, sampling for the incidence of head excision assessment on senescence could be consistent with an early stage of bud development in which there would be no evident differences between the two conditions (Zavaleta-Mancera et al. 1999a; Zavaleta-Mancera et al. 1999b; Thomas \& Donnisson 2000).

\begin{tabular}{|c|c|c|c|c|c|c|c|c|c|c|c|}
\hline \multirow[b]{3}{*}{ Treatment } & \multirow[b]{3}{*}{ Samples } & \multicolumn{6}{|c|}{ SAGs genes (Gepstein et al. 2003) } & \multicolumn{4}{|c|}{ RGs genes (Fernandez et al. 2011) } \\
\hline & & \multicolumn{2}{|c|}{$\begin{array}{c}\text { R2 } \\
\text { (AN At4g32940) }\end{array}$} & \multicolumn{2}{|c|}{$\begin{array}{c}\text { D3 } \\
\text { (AN At5g60360) }\end{array}$} & \multicolumn{2}{|c|}{$\begin{array}{c}\text { D4 } \\
\text { (AN At1g18210) }\end{array}$} & \multicolumn{2}{|c|}{$\begin{array}{c}\text { a-TUB } \\
\text { (AN AF401481.1) }\end{array}$} & \multicolumn{2}{|c|}{$\begin{array}{c}\text { EF-1 } \alpha \\
\text { (AN CAA37212.1) }\end{array}$} \\
\hline & & $\mathrm{Cq}$ & $\mathrm{CV}$ & $\mathrm{Cq}$ & $\mathrm{CV}$ & $\mathrm{Cq}$ & $\mathrm{CV}$ & $\mathrm{Cq}$ & $\mathrm{CV}$ & $\mathrm{Cq}$ & $\mathrm{CV}$ \\
\hline C.L1 & 3 & 30.49 & 2.5 & 31.06 & 5.0 & 28.74 & 3.9 & 33.69 & 1.7 & 30.08 & 2.6 \\
\hline C.L2 & 3 & 30.00 & 0.8 & 30.19 & 3.8 & 27.42 & 4.5 & 34.20 & 1.9 & 25.57 & 7.2 \\
\hline FE.L1 & 3 & 30.46 & 3.9 & 28.96 & 4.3 & 26.42 & 6.6 & 33.52 & 2.9 & 27.16 & 1.7 \\
\hline FE.L2 & 3 & 29.28 & 0.6 & 29.13 & 1.1 & 24.84 & 2.7 & 33.32 & 2.6 & 26.73 & 12.9 \\
\hline D.L1 & 3 & 30.45 & 2.1 & 30.31 & 1.7 & 26.10 & 5.1 & 33.67 & 0.2 & 27.80 & 6.7 \\
\hline D.L2 & 3 & 29.75 & 2.0 & 29.12 & 5.5 & 24.98 & 1.5 & 33.38 & 4.5 & 30.07 & 5.7 \\
\hline
\end{tabular}

Table 1. Average Cq and CV value for R2, D3 and D4 genes and the two best ranked RGs for three biological replicates per treatment (Fernandez et al. 2011).

As a result from these analyses, the adjustment of the sampling time and frequency turns out as a highly critical point in studying gene expression profiling of candidate genes, according to the treatments on evaluation. Earlier samplings are necessary to detect the trigger moment of different candidate genes for leaf senescence process in sunflower. Considering Table 1, it is worth mentioning that relative quantification of a putative SAG would be overestimated if EF-1 $\alpha$ (AN CAA37212.1) would have been used as a single reference gene, which reinforces the importance of normalizing against two or more experimentally validated RG when quantifying transcripts (Fernandez et al. 2011). In order to reach a wider search of new candidate genes, an additional set of new published genes were considered and their predicted functionality was evaluated with the aim to give new insights into this process. For a preliminary detection of potential SAGs, classical macromolecular degradation SAGs were discarded of our analysis because they are probably not associated with early leaf senescence, but with induced changes later in the time course of the process. In this sense, Chlorophyll-Binding Proteins (CBP) were first isolated in soybean (Guiamet et al. 1991) whereas SAGs N4 and SAG12 were detected by differential screen of Arabidopsis leaf senescence cDNA libraries (Gan \& Amasino 1995; Park 
et al. 1998). They encode an apparent cysteine proteinase and their expression is highly senescence specific (Lohman et al. 1994; Gan \& Amasino 1995; Martinez et al. 2007) mainly localized in small senescence associated vacuoles (Saeed et al. 2003; Otegui et al. 2005). However, neither SAG12 nor SEN4 match any full sequence in sunflower with a high identity score level. For this reason, a second set of candidate SAGs (OsNAC5, WRKY6, ORS1 YUCCA6, among others) (Ülker \& Somssich 2004; Balazadeh et al. 2011; Kim et al. 2011; Song et al. 2011) was compared against Helianthus annuus unigene collection but a low score level to Helianthus annuus sequences was detected. Therefore, other candidate genes were added to be functionally tested for early leaf senescence in sunflower. The special case of transcription factors (TFs) as crucial regulators of gene expression by binding to distinct cis-elements, generally located in the $5^{\prime}$ upstream regulatory regions of target genes, were specially considered to detect early senescence leaf makers (Balazadeh et al. 2008). NAC transcription factors related to senescence have been recently identified in model species and they play a relevant role in the regulation of development of leaf senescence related to programmed cell death (Olsen et al. 2005; Kim et al. 2009; Balazadeh et al. 2010; Hu et al. 2010; Nuruzzaman et al. 2010; Balazadeh et al. 2011). A single one NAC gene (AtNAP), also called NAC2 or ANAC029 (Guo \& Gan 2006), has been the main one identified to control leaf senescence, although approximately 20 NAC genes in Arabidopsis shown high expression in senescing leaves (Guo et al. 2004; Lin \& Wu 2004). ROS reagents acting as senescence stimulus were also reported within a narrow cross talk involving hormones and TFs both in natural and stress-related senescence (Rivero et al. 2007; Khanna-Chopra 2011), indicating that elevated ROS levels might be detected as a potential signal of senescence induction. Under this assumption ORE1, a NAC transcription factor that has been extensively studied in recent years, has been described as strongly related to leaf senescence, probably coevolving genes with ORS1 (Ooka et al. 2003). This TF can be considered a new further positive regulator of senescence in conjunction with AtNAP (Balazadeh et al. 2011), controlling leaf senescence in Brassicaceae. In Arabidopsis, ORE1 mutants show a delay in leaf senescence whereas overexpression through an inductive promoter, accelerates senescence in relation to wild type plants (Balazadeh et al. 2010) and the forest tree Populus trichocarpa in which approximately 2,900 TFs were reported (Hu et al. 2010) and will be soon tested for sunflower candidate SAG detection. Microarray studies showed that $46 \%$ of up regulated genes in Arabidopsis ORE1 overexpression lines, are known as senescence-associated genes, including many genes previously reported as senescence regulated, suggesting an important role in the development of the senescence process (Balazadeh et al. 2010). In wheat, it was reported that NAC TFs not only accelerate senescence but also improve nutrient remobilization by increasing protein, iron and zinc content (Uauy et al. 2006). ORE1 expression is under control of the ethylene signaling pathway and is subjected to regulation by miRNA164, being negatively regulated. When the leaf is young, miR164 transcripts remain at high levels regulating the expression of ORE1 but during the leaf aging process, its expression gradually decreases, thus increasing the expression of ORE1 (Kim et al. 2009).

In sunflower, a sequence similar ORE1 has been detected in the Helianthus annuus unigene collection developed at INTA (ATGC Sunflower Database: http://bioinformatica.inta.gov.ar/ATGC) with a Blast score of 96 and E-value of e-10 (Altschul et al. 1990). Expression profiles studies at different sunflower developmental stages showed a significant increase of putative ORE1 transcripts in samples close to anthesis stage, prior to the start of the first symptoms of senescence, when the critical period 
of grain filling has already begun (Figure 2). These results are consistent with those observed in Arabidopsis, and turn this gene a potential functional marker of the progress of senescence, representing an important tool for future implications in the sunflower crop improvement (Moschen et al. 2010). In order to confirm in-situ the functionality of this putative ORE1 gene in sunflower, a comparative bioinformatics analysis has been performed using the Blastx algorithm (Altschul et al. 1990), searching for proteins in the database at the National Center for Biotechnology Information NCBI (http://www.ncbi.nlm.nih.gov/), using as query the nucleotide sequence of putative sunflower ORE1. These results showed a high similarity with ORE Arabidopsis protein (GI 15241819) suggesting a possible role of this gene as NAC transcription factor. Moreover, searches for functional protein domains in Pfam (http://pfam.sanger.ac.uk/) revealed that main protein domain in sunflower ORE1-like gene sequence corresponds to the family of NAM transcription factors (No Apical Meristem) (pfam02365), as well as the Arabidopsis ORE1 sequence pfam02365. Figure 3 shows Arabidopsis alignments and putative sunflower ORE1 proteins against Pfam NAC domain. Others relevant in-silico candidates for a putative sunflower SAG are: RAV1 gene, a transcription factor whose expression is closely associated with leaf maturation and senescence (Woo et al. 2010), which has been detected with a high score level and statistically low E-value, and CAT2, a member of a small gene $\mathrm{H}_{2} \mathrm{O}_{2}$ detoxifying enzyme family, widely characterized in Arabidopsis (Gergoff et al. 2010; Smykowski et al. 2010), although not yet tested in sunflower.

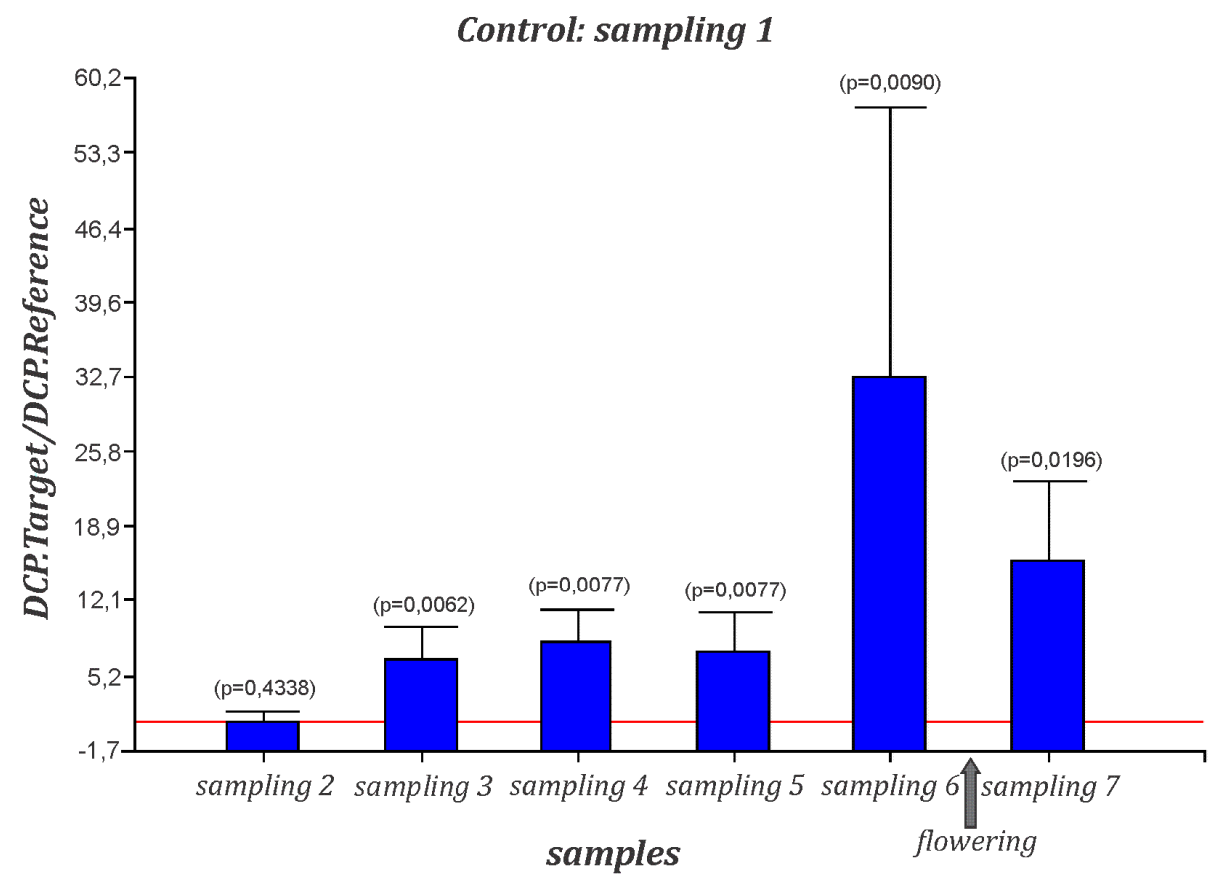

Fig. 2. Differential expression of putative sunflower ORE1 gene in subsequent samplings, taking as control condition sampling number 1 and referred to a-TUB expression level (Moschen et al. 2010). 


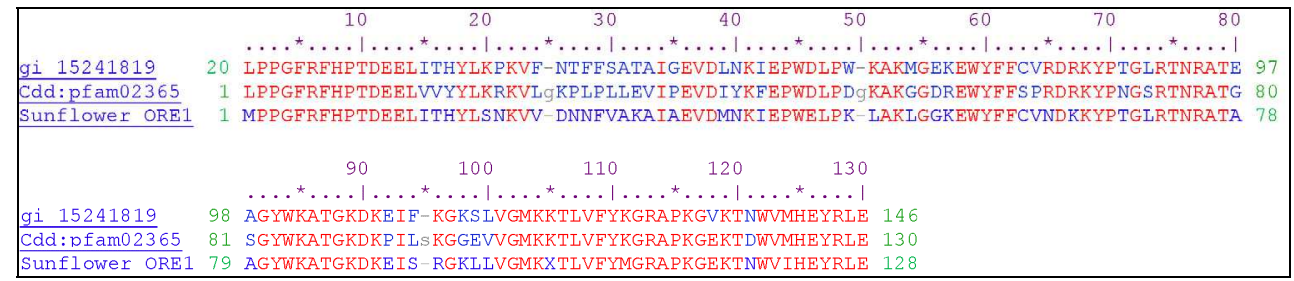

Fig. 3. Arabidopsis NAM domain and putative sunflower ORE1 protein alignment (pfam02365) (http://www.ncbi.nlm.nih.gov/cdd/).

As mentioned above, the execution of the senescence process consists of multiple interconnecting pathways which regulate and/or modulate this series of orderly steps; therefore different transcription factors play an important role as regulators of these pathways. Recently, a list of transcription factors that regulate leaf senescence in Arabidopsis has been published (Balazadeh et al. 2008). The search for tentative orthologous genes in the Helianthus annuus unigene collection, using Blast algorithm, led to the identification of 42 genes with a significant score value to transcription factors like NAC, MYB, WRKY, ARP among others, some of these genes are being studied their expression patterns by qPCR.

\section{Concerted gene expression studies to elucidate sunflower senescence process}

Although microarray technology started a new era of high-throughput transcriptomic analysis approximately ten years ago, starting with 8,000 printed genes by Affymetrix in Arabidopsis thaliana (Zhu \& Wang 2000) and later on scaling up to 45,000 printed genes in rice (Jung et al. 2008) and 90,000 in Brassica (Trick et al. 2009), next generation sequencing (NGS) technologies are nowadays opening a new era of even deeper understanding of genomics and transcriptomics in different species . However, for the foreseeable future both technologies will coexist each focusing on different tasks, or by complementing biological and value information (Fenart et al. 2010) or by designing dedicated oligonucleotide arrays to support functional studies on a specified pathway/developmental stage (Kusnierczyk et al. 2008; Cosio \& Dunand 2010; Ott et al. 2010). One obvious application of microarray technology is the transcriptional profiling in species that have neither their own genome sequenced nor a reference genome from a closely related species. For some of these species a commercial microarray based on an existing own-design are available (Agilent, Affimetrix, Nimblegen, etc) (Close et al. 2004; Li et al. 2008; Martinez-Godoy et al. 2008; Mascarrell-Creus et al. 2009; Trick et al. 2009; Booman et al. 2010; Curtiss et al. 2011). Sunflower is a species that fits into this framework, even though a genome sequence initiative is in progress (Kane et al. 2011), there is no reference genome available. In this case, the only source of functional information is limited to ESTs databases, which in the case of cultivated sunflower is rather extensive, more than 133,000 ESTs are publicly available (http://ncbi.nlm.nih.gov/dbEST/dbEST_summary.html) covering libraries prepared from several lines and cultivars (Table2). However, it should also be noted that ESTs libraries tend to be significantly contaminated with vector sequences and chimeras, and have relatively low quality DNA information derived from the library sequencing strategy which prioritizes obtaining a large number of single pass sequences, being necessary to standardize a set of bioinformatics routines in order to clean and decontaminate public raw sequences (Figure 4). 
Microarrays using ESTs and full length gene sequences allowed SAGs identification during leaf senescence at the genome-wide scale in Arabidopsis and other plants (Lim et al. 2007). In parallel, other high-throughput system has been assayed in other species: cDNA macro and microarray were developed for sunflower to study sunflower seed development (Hewezi et al. 2006) and the response to biotic (Alignan et al. 2006), and abiotic stresses (Hewezi et al. 2006; Roche et al. 2007; Fernandez et al. 2008). This last work reported for the first time, a concerted study on gene expression in early responses to chilling and salinity using a fluorescence microarray assay based on organ-specific unigenes in sunflower. These two strategies, although useful, are limited to the analysis of a limited set of genes. Currently, the shortage of candidate genes underlying agronomically important traits represents one of the main drawbacks in sunflower molecular breeding. In this context, functional tools which allow concerted transcriptional studies, as high density oligonucleotide microarray, strongly support the discovery and characterization of novel genes. Oligonucleotide-based chips not only allow the analysis for a whole transcriptome but they are also considered more accurate than cDNA-based chips due to the reduction of manipulation steps (Larkin et al. 2005; Lai et al. 2006). The possibility to implement this technology on any custom array system like Agilent, Nimblegen, and others, has the potential to create a very useful tool for gene discovery in orphan crops (Nazar et al. 2010; Ophir et al. 2010). In addition, the use of longer probe format represents a major advantage of Agilent oligonucleotide microarrays over others technologies based on a higher stability in the presence of sequence mismatches, being consequently, more suitable for the analysis of highly polymorphic regions (Hardiman 2004).

In general, the analysis of complex biological processes based on a gene by gene approach seldom leads to limited or erroneous conclusions requiring an alternative approach based on systemic association studies. Under this assumption, new insights into molecular senescence events might be cleared up by high-resolution microarray data, for example, considering different points of leaf development (Breeze et al. 2011) or predicting putative SAGs by tissue and functional categories (Thomas et al. 2009). In our lab, a public and proprietary datasets of $H$. annuus $L$. ESTs have been used to create a comprehensive sunflower unigene collection. This dataset comprises 34 cDNAs libraries available from different cultivars, various tissues and anatomical parts, from plants grown at different physiological conditions.

Figure 4 describes the routines applied for the $H$. annuus $L$ unigene collection design.

A Digital Gene Expression Profile (Audic \& Claverie 1997) was assayed with the EST public data in order to detect any bias that would be pseudo-enriching the gene index by full representation of one library over another considering full public ESTs derived from public collections (Table 2). This analysis ("digi-Northern") detected that ESTs were equally represented among differential cDNA libraries, showing that the $H$. annuus unigene collection generated would be fully represented by different transcripts, lacking of a potential enrichment or overestimation among organ-specific ESTs libraries. This unigene collection was used to design the first custom sunflower oligonucleotide-based microarray based on Agilent technology as a main goal for functional genomics approaches, generated within the frame of a collaborative project involving Argentinean research sunflower groups (Sunflower PAE Consortium), Facultad de Agronomía (UBA) and the Bioinformatics facility at the Principe Felipe Institute, Valencia , España. A Chado-based database (Mungall et al. 
2007) and a visualization tool call ATGC (Clavijo et al., unpublished) was developed to integrate and browse sunflower transcriptome information. Figure 5 shows the output of the ATGC interface for one functional annotated sunflower unigene.

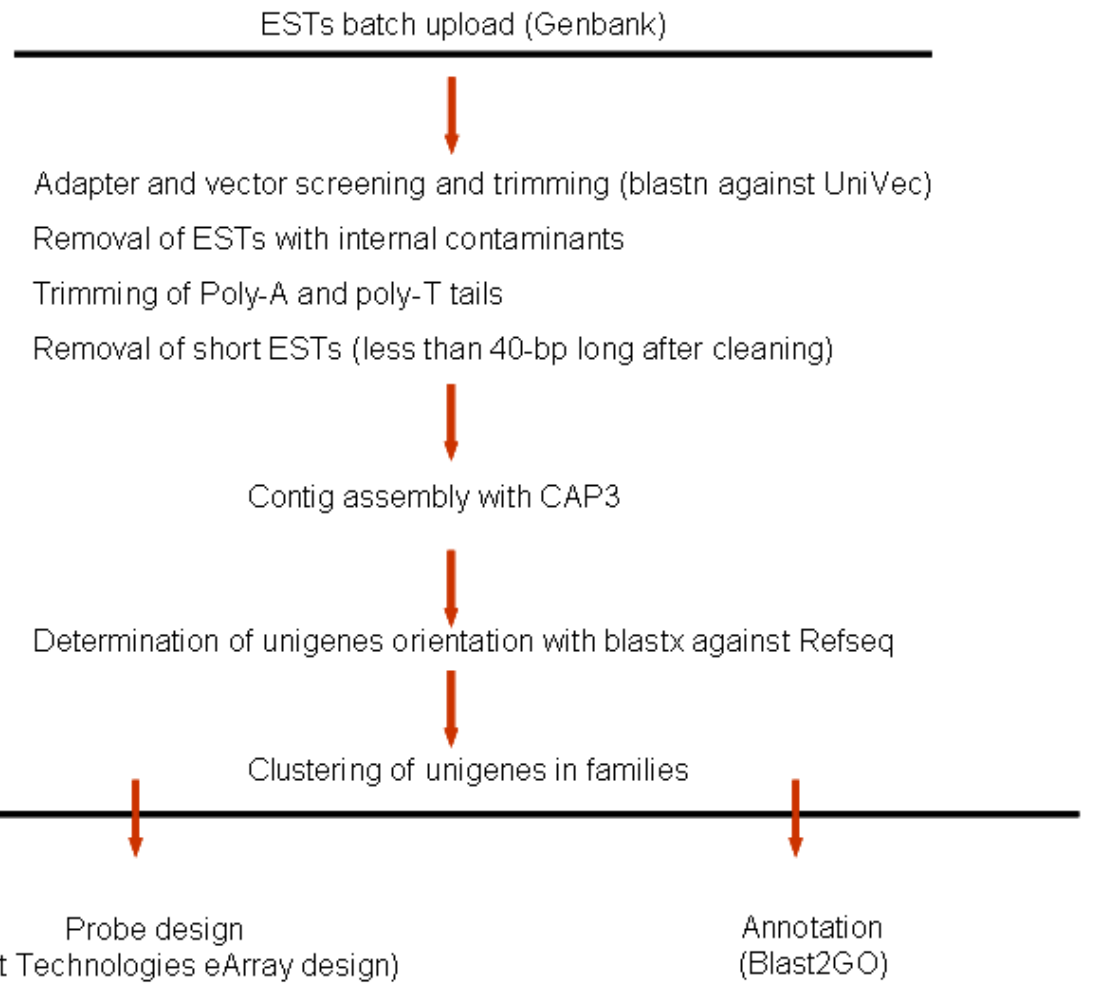

Fig. 4. Bioinformatics routines applied to design Helianthus annuus unigene collection (http://bionformatica.inta.gov.ar/ ATGC/).

Sunflower gene expression chip probes were designed using eArray® web application (Agilent Technologies). For this instance, two probe sets were designed: one including noncontrol specific probes for the sequences of sunflower unigene collection and a second control probe set consisting in 74 probes derived from 80 differentially expressed sunflower genes identified in a previously work (Fernandez et al. 2008). The latest group was used as 'Replicate Controls' with 10 replicates each. To utilize the full capacity of the microarray, probes were randomly selected to be represented in duplicate in the final design, which also included Agilent Technologies' standard panel of quality control and spike-in probes. This design was then used to manufacture microarrays using Agilent SurePrint ${ }^{\mathrm{TM}}$ Technology in the $4 \times 44$ format. Agilent's microarrays include the Spike-In Kit that consists of a set of 10 positive control transcripts optimized to anneal to complementary probes on the microarray, minimizing self-hybridization or cross-hybridization. This work contemplates the microarray validation through diverse differential expression analysis in order to analyze early senescence in sunflower through a classical approach and a pipeline-based 
methodology. Differential gene expression was also carried out using the limma package (Smyth 2004). Multiple testing adjustments of p-values was done according to Benjamini and Hochberg methodology (Benjamini \& Hochberg 1995). Gene set analysis was carried out according to the Gene Ontology terms using FatiScan (Al-Shahrour et al. 2007) integrated in Babelomics suite (Al-Shahrour et al. 2005).

\begin{tabular}{|l|l|}
\hline \multicolumn{1}{|c|}{ Library ID } & \multicolumn{1}{c|}{ Developmental stage } \\
\hline HaSSH & $\begin{array}{l}\text { Molecular characterization of phosphorus- } \\
\text { responsive genes in sunflower }\end{array}$ \\
\hline CCF (STU) & $\begin{array}{l}\text { EST sequences from several different } \\
\text { strains/cultivars }\end{array}$ \\
\hline $\begin{array}{l}\text { QH-RHA 280/QH_ABCDI } \\
\text { sunflower RHA801 }\end{array}$ & $\begin{array}{l}\text { shoots/hulls/flowers environmental } \\
\text { stress/chemical induction }\end{array}$ \\
\hline $\begin{array}{l}\text { CHA(XYZ) common wild } \\
\text { sunflower }\end{array}$ & girasol silvestre (wild sunflower) \\
\hline HaHeaS & heart-shaped embryo vs cotyledonary embryo \\
\hline HaHeaR & heart-shaped embryo \\
\hline HaCotR & cotyledonary embryo \\
\hline HaGlbR & globular embryo \\
\hline HaDevS1 & 4 days after self-pollination embryo \\
\hline HaDevS2 & 7 days after self-pollination embryo \\
\hline HaDevR1 & leaves \\
\hline HaDevR2 & terminal bud \\
\hline HaDevR3 & stem \\
\hline HaDevR6 & embryo \\
\hline HaDevR5 & 4 days after self-pollination embryo \\
\hline HaDevR8 & 15 days after self-pollination embryo \\
\hline HaDis & unknown/cotyledons/ (Genoplante) \\
\hline HaSemS4 & hypocotyl \\
\hline HaDpsR1 & hypocotyl \\
\hline HaDplR2 & hypocotyl 1-5 days \\
\hline HaDplR & protoplast \\
\hline HaERF & embryo \\
\hline HaERS & embryo \\
\hline HaR & INTA: organ-specific cDNA libraries (root) \\
\hline HaT & INTA: organ-specific cDNA libraries (stem) \\
\hline HaEF & INTA: organ-specific cDNA libraries (early flower) \\
\hline HaF & INTA: organ-specific cDNA libraries (flower) \\
\hline HaH & INTA: organ-specific cDNA libraries (leaf) \\
\hline & \\
\hline
\end{tabular}

Table 2. Public cDNA libraries deposited in GenBank for which H. annuus unigene collection was designed. 
INTA

Feature detail for Contig100015

Sequence Information

Sequence size for Contig 100015 is 1079 chars

$>$ Contig100015

GCAATGGATAAGCACT CAACCACT AACTACT AGCAATAGT GAATACTCLCCACAAATCCAT

TCAGT GGT TECTTICCACCACACATCAAAGCAATGGAT AAACAACT CT TTGECGGAGTCGC

AAATTCCAGCAAGAACAAAARGAT CTITTATCATATTCGCT PCAATCCT ACTPGTCGCGGC

AGAGATCCGCATT GT GGCT GGAGT CAACTCCAAAACCACCAACACTCAAT CCAACAACAT

AAGAGCATCCGCGGCT CACACCAT CGT GAAAT CATCATGTAGCGT CACCCTCCACCCCGA

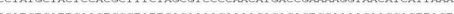

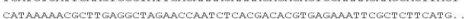

Get secuence as tasta file

Contig Assembly

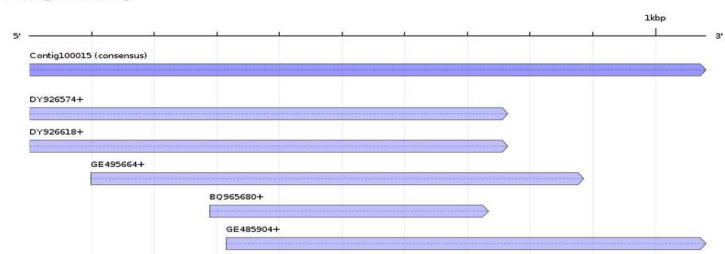

Go Annotation
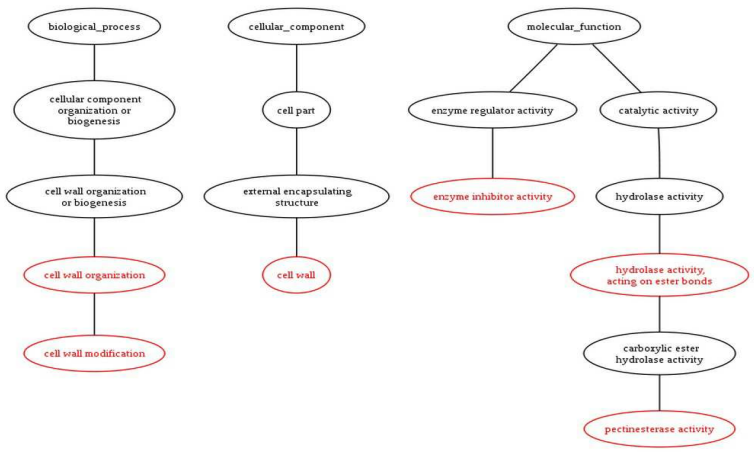

Direct Annotation:

GO:0042545 cell wall modification (via Interpro run 1 )

- Go:0005618 cell wall (via interpro run 1 )

G0:0004857 enzyme inhibitor activity (via Interpro run 1 )

- Go:0030599 pactunesterase activty (via interpro run 1 )

Go:0016788 hyarolase acturty, acting on ester bonds (Ma Blast2 2 o run

hherited Annotation

- GO:0052689: carboxylic ester hydrolase activity

- GO:0071554 cell well organization or biogenesis

G0:0071840. celluler component orgenization or biogenesis

Go:0003674 molecular_function

- Go:0005575 cellular

Go:004464 cell part

- G0.0016787 hydrolasa activiny

60:0003824 catelytic activity

- G0:0030312 external oncapsulating stract

Go:0030234 enzymie requlator ectivity

\section{Blast Matches}

Match

accession

XP_0102304257 predicted protein [Populus trichocarpal

predicted protein [Populus trichocarpa]

pectin methyl esterase [solanum tuberosum]

$\underline{043143}$

AADOQ2B3

$\frac{\mathrm{AAOB} 5700}{\mathrm{~PB} 3948}$

004886

$\triangle A B 57670$

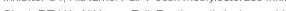

pectin methylesterase [Solanum lycopersicum]

pectinesterase [Citrus sinensis]

ctinesterase [Citrus sinensis]

RecName Ful=Pectinesterase/pertunesterase innibitor U1: Includés Rec Neme. Full=Pectinesterase

RecName: Full=Pectinesterase 3; Short=PE 3; Altvame: Full=Pectin mottylesterase 3; Flags: Precursor

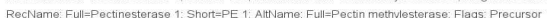

Norm Raw Score

score

$73.0 \quad 302387504484$

$73.0 \quad 302367504464$

$\begin{array}{lll}748.0 & 292737515066 \\ 7360 & 288115120155\end{array}$

$736.0 \quad 280.115120155$

$712.0 \quad 278.870330333$

$709.0 \quad 277.714731605$

27732953203

$08.0 \quad 2773295320$

Fig. 5. ATGC view for an annotated sunflower unigene. 


\section{Conclusions and perspectives}

Knowing the time of onset the the cascade of events that trigger senescence could determine the causes of this process and generate molecular tools to facilitate future interventions on it, useful for application in assisted breeding of this crop with major growing oil impact in the world.

The sunflower chip, designed within a PAE Consortium made up of six laboratories and one private company working in different areas of research and development, was validated by means of the analysis of global changes in gene expression profiles in response to water deficit as a physiological event which induces senescence, taken as a model experiment, for which reference genes have also been previously identified (Fernandez et al. 2011). This high-throughput transcriptome tool will allow the discovery, identification and analysis of a new set of putative SAGs for sunflower which would bring novel insights for this process. The integrated analysis of transcriptional and metabolic profiles will allow the identification of concerted regulation of distinct metabolic pathways facilitating the discovery of robust candidate genes and key metabolic pathways involved in the outbreak of the early senescence process in sunflower leaves. We expect that the integration of the information generated by this project will allow the construction of the quantitative predictive model of senescence in sunflower, under field and greenhouse conditions, which is required to interpret the regulation of the underlying complex biological processes. There will also be practical applications in directed gene discovery for other important agronomic traits involving plant responses to biotic and abiotic stresses. Finally, this project will have impact based in the establishment of microarray technologies and metabolic analysis, as well as on the knowledge of appropriated statistical and bioinformatics procedures supporting functional genomics ranging from the transcriptome to the metabolome.

\section{Acknowledgment}

This research was supported by CONICET PIP 5788, ANPCyT/FONCYT, Préstamo BID PICT 15-32905 and PICT 0960, INTA-PE AEBIO 241001and 245001, INTA-PE AEBIO 245732, INTA-AEBI0 243532, INTA PN CER 1336 and UNMdP, AGR212, AGR260. Lic. Sebastián Moschen holds a fellowship from ANPCyT to support his PhD studies whereas Dr. PdCF, Dr. RAH, Dr. NBP are career members of the Consejo Nacional de Investigaciones Científicas y Técnicas (CONICET, Argentina) and INTA researchers.

\section{References}

Aguera, E., P. Cabello and P. de la Haba (2010). "Induction of leaf senescence by low nitrogen nutrition in sunflower (Helianthus annuus) plants." Physiol Plant 138(3): 256-267.

Aguirrezábal, L. A. N. A., Y. Lavaud, G. A. A. Dosio, N. Izquierdo, F. Andrade and L. González (2003). "Intercepted solar radiation during seed filling determines sunflower weight per seed and oil concentration." Crop Science 43: 152-161.

Al-Shahrour, F., L. Arbiza, H. Dopazo, J. Huerta-Cepas, P. Minguez, D. Montaner and J. Dopazo (2007). "From genes to functional classes in the study of biological systems." BMC Bioinformatics 8(1): 114. 
Al-Shahrour, F., P. Minguez, J. M. Vaquerizas, L. Conde and J. Dopazo (2005). "BABELOMICS: a suite of web tools for functional annotation and analysis of groups of genes in high-throughput experiments." Nucleic Acids Res 33(Web Server issue): W460-464.

Alignan, M., T. Hewezi, M. Petitprez, G. Dechamp-Guillaume and L. Gentzbittel (2006). "A cDNA microarray approach to decipher sunflower (Helianthus annuus) responses to the necrotrophic fungus Phoma macdonaldii." New Phytol 170(3): 523-536.

Altschul, S., W. Gish, W. Miller, E. Myers and D. Lipman (1990). "Basic local alignment search tool." Journal of Molecular Biology 215: 403-410.

Andersen, C., J. Jensen and T. Orntoft (2004). "Normalization of real-time quantitative reverse transcription-PCR data: a model-based variance estimation approach to identify genes suited for normalization, applied to bladder and colon cancer data sets." Cancer Res 64: 5245-5250.

Audic, S. and J. M. Claverie (1997). "The significance of digital gene expression profiles." Genome Research 7(10): 986-995.

Balazadeh, S., M. Kwasniewski, C. Caldana, M. Mehrnia, M. I. Zanor, G. P. Xue and B. Mueller-Roeber (2011). "ORS1, an HO-responsive NAC transcription factor, controls senescence in Arabidopsis thaliana." Mol Plant 4(2): 346-360.

Balazadeh, S., D. M. Riaño-Pachón and B. Mueller-Roeber (2008). "Transcription factors regulating leaf senescence in Arabidopsis thaliana." Plant Biology 10((Suppl. 1)): 63-75.

Balazadeh, S., H. Siddiqui, A. D. Allu, L. P. Matallana-Ramirez, C. Caldana, M. Mehrnia, M.I. Zanor, B. Köhler and B. Mueller-Roeber (2010). "A gene regulatory network controlled by the NAC transcription factor ANAC092/AtNAC2/ORE1 during saltpromoted senescence." The Plant Journal doi: 10.1111/j.1365-313X.2010.04151.x.

Balazadeh, S., H. Siddiqui, A. D. Allu, L. P. Matallana-Ramirez, C. Caldana, M. Mehrnia, M. I. Zanor, B. Kohler and B. Mueller-Roeber (2010). "A gene regulatory network controlled by the NAC transcription factor ANAC092/AtNAC2/ORE1 during saltpromoted senescence." Plant J 62(2): 250-264.

Balazadeh, S., A. Wu and B. Mueller-Roeber (2010). "Salt-triggered expression of the ANAC092-dependent senescence regulon in Arabidopsis thaliana." Plant Signal Behav 5(6): 733-735.

Benjamini, Y. and Y. Hochberg (1995). "Controlling the False Discovery Rate: A Practical and Powerful Approach to Multiple Testing." Journal of the Royal Statistical Society 57(1): 289-300.

Booman, M., T. Borza, C. Y. Feng, T. S. Hori, B. Higgins, A. Culf, D. Leger, I. C. Chute, A. Belkaid, M. Rise, A. Kurt Gamperl, S. Hubert, J. Kimball, R. J. Ouelelette, S. C. Johnson, S. Bowman and M. L. Rise (2010). "Development and Experimental Validation of a 20K Atlantic Cod (Gadus morhua) Oligonucleotide Microarray Based on a Collection of over 150,000 ESTs." Mar Biotechnol DOI: 10.1007/s10126-010-93356.

Breeze, E., E. Harrison, S. McHattie, L. Hughes, R. Hickman, C. Hill, S. Kiddle, Y.-s. Kim, C. A. Penfold, D. Jenkins, C. Zhang, K. Morris, C. Jenner, S. Jackson, B. Thomas, A. Tabrett, R. Legaie, J. D. Moore, D. L. Wild, S. Ott, D. Rand, J. Beynon, K. Denby, A. Mead and V. Buchanan-Wollaston (2011). "High-Resolution Temporal Profiling of Transcripts during Arabidopsis Leaf Senescence Reveals a Distinct Chronology of Processes and Regulation." The Plant Cell Online 23(3): 873-894. 
Buchanan-Wollaston, V., S. Earl, E. Harrison, E. Mathas, S. Navabpour, T. Page and D. Pink (2003). "The molecular analysis of leaf senescence -a genomic approach." Plant Biotechnology Journal 1: 3-22.

Buermans, H., Y. Ariyurek, G. van Ommen, J. den Dunnen and P. 't Hoen (2010). "New methods for next generation sequencing based microRNA expression profiling." BMC Genomics 11(1): 716.

Cabello, P., E. Agüera and P. De la Haba (2006). "Metabolic changes during natural ageing in sunflower (Helianthus annuus) leaves: expression and activity of glutamine synthetase isoforms are regulated differently during senescence." Physiol Plant 128: 175-185.

Close, T. J., S. I. Wanamaker, R. A. Caldo, S. M. Turner, D. A. Ashlock, J. A. Dickerson, R. A. Wing, G. J. Muehlbauer, A. Kleinhofs and R. P. Wise (2004). "A New Resource for Cereal Genomics: 22K Barley GeneChip Comes of Age." Plant Physiology 134: 960968.

Conesa, A., S. Gotz, J. M. Garcia-Gomez, J. Terol, M. Talon and M. Robles (2005). "Blast2GO: a universal tool for annotation, visualization and analysis in functional genomics research." Bioinformatics 21(18): 3674-3676.

Cosio, C. and C. Dunand (2010). "Transcriptome analysis of various flower and silique development stages indicates a set of class III peroxidase genes potentially involved in pod shattering in Arabidopsis thaliana." BMC Genomics 11(1): 528.

Curtiss, J., L. Rodriguez-Uribe, J. M. Stewart and J. Zhang (2011). "Identification of differentially expressed genes associated with semigamy in Pima cotton (Gossypium barbadense L.) through comparative microarray analysis." BMC Plant Biol 11: 49.

De la Vega, A., M. A. Cantore, N. N. Sposaro, N. Trapani, M. Lopez Pereira and A. J. Hall (2011). "Canopty stay green and yield in non stressed sunflower." Fields Crop Researchs 121: 175-185.

Dezar, C. A., G. M. Gago, D. H. Gonzalez and R. L. Chan (2005). "Hahb-4, a sunflower homeobox-leucine zipper gene, is a developmental regulator and confers drought tolerance to Arabidopsis thaliana plants." Transgenic Res 14(4): 429-440.

Dhahbi, J. M., H. Atamna, D. Boffelli, W. Magis, S. R. Spindler and D. I. K. Martin (2011). "Deep Sequencing Reveals Novel MicroRNAs and Regulation of MicroRNA Expression during Cell Senescence." PLoS ONE 6(5): e20509.

Dosio, G. A., H. Rey, J. Lecoeur, N. G. Izquierdo, L. A. Aguirrezabal, F. Tardieu and O. Turc (2003). "A whole-plant analysis of the dynamics of expansion of individual leaves of two sunflower hybrids." J Exp Bot 54(392): 2541-2552.

Dosio, G. A. A. and L. A. N. Aguirrezábal (2004). Variaciones del rendimiento en girasol. Identificando las causas. Revista Agromercado, Cuadernillo de girasol. 90: 7-10.

Dosio, G. A. A., L. A. N. A. Aguirrezábal, F. H. Andrade and P. V. R. (2000). "Solar radiation intercepted during seed filling and oil production in two sunflower hybrids." Crop Science 40(1637-1644).

Espinoza, C., C. Medina, S. Somerville and P. Arce-Johnson (2007). "Senescence-associated genes induced during compatible viral interactions with grapevine and Arabidopsis." Journal of Experimental Botany 58(12): 3197-3212.

Ewing, R. M. and J. M. Claverie (2000). "EST databases as multi-conditional gene expression datasets." Pac Symp Biocomput: 430-442. 
Fenart, S., Y.-P. Assoumou Ndong, J. Duarte, N. Rivière, J. Wilmer, O. van Wuytswinkel, A. Lucau, E. Cariou, G. Neutelings, L. Gutierrez, B. Chabbert, X. Guillot, R. Tavernier, S. Hawkins and B. Thomasset (2010). "Development and validation of a flax (Linum usitatissimum L.) gene expression oligo microarray." BMC Genomics 11(592).

Fernandez, P., J. Di Rienzo, L. Fernandez, H. Hopp, N. Paniego and H. R.A. (2008). "Transcriptomic identification of candidate genes involved in sunflower responses to chilling and salt stresses based on cDNA microarray analysis." BMC Plant Biology $8(11)$.

Fernandez, P., J. Di Rienzo, S. Moschen, D. GAA, L. Aguirrezabal, H. Hopp, N. Paniego and H. R.A. (2011). "Comparison of predictive methods and biological validation for qPCR reference genes in sunflower leaf senescence transcript analysis." Plant Cell Report 30(1): 63-74.

Fernandez, P., N. Paniego, S. Lew, H. E. Hopp and R. A. Heinz (2003). "Differential representation of sunflower ESTs in enriched organ-specific cDNA libraries in a small scale sequencing project." BMC Genomics 4(1): 40.

Gan, S. and R. M. Amasino (1995). "Inhibition of leaf senescence by autoregulated production of cytokinin." Science 270(5244): 1986-1988.

Gan, S. and R. M. Amasino (1997). "Making sense of senescence." Plant Physiology 113: 313319.

Gepstein, S., G. Sabehi, M.-J. Carp, T. Hajouj, M. F. O. Nesher, I. Yariv, C. Dor and M. Bassani (2003). "Large-scale identification of leaf senescence-associated genes." The Plant Journal 36: 629-642.

Gergoff, G., A. Chaves and C. G. Bartoli (2010). "Ethylene regulates ascorbic acid content during dark-induced leaf senescence." Plant Science 178: 207-212.

Guiamet, J. J., E. Schwartz, E. Pichersky and L. D. Nooden (1991). "Characterization of Cytoplasmic and Nuclear Mutations Affecting Chlorophyll and ChlorophyllBinding Proteins during Senescence in Soybean." Plant Physiol 96(1): 227-231.

Guo, Y., Z. Cai and S. Gan (2004). "Transcriptome of Arabidopsis leaf senescence." Plant, Cell and Environment 27: 521-549.

Guo, Y. and S. Gan (2006). "AtNAP, a NAC family transcription factor, has an important role in leaf senescence." The Plant Journal 46(4): 601-612.

Hardiman, G. (2004). "Microarray platforms--comparisons and contrasts." Pharmacogenomics 5(5): 487-502.

Hewezi, T., M. Leger, W. El Kayal and L. Gentzbittel (2006). "Transcriptional profiling of sunflower plants growing under low temperatures reveals an extensive downregulation of gene expression associated with chilling sensitivity." J Exp Bot 57(12): 3109-3122.

Hewezi, T., M. Petitprez and L. Gentzbittel (2006). "Primary metabolic pathways and signal transduction in sunflower (Helianthus annuus L.): comparison of transcriptional profiling in leaves and immature embryos using cDNA microarrays." Planta 223(5): 948-964.

Hörtensteiner, S. (2006). "Chlorophyll degradation during senescence." The Annual Review of Plant Biology 57: 55-77.

Hu, R., G. Qi, Y. Kong, D. Kong, Q. Gao and G. Zhou (2010). "Comprehensive Analysis of NAC Domain Transcription Factor Gene Family in Populus trichocarpa." BMC Plant Biology 10(145). 
Jobit, C., A. Boisson, E. Gout, C. Rascle, M. Feyre, P. Cotton and R. Bligny (2007). "Metabolic processes and carbon nutrient exchanges between host and pathogen sustain the disease development during sunflower infection by Sclerotinia sclerotiorum." Planta 226: 251-265.

Jung, K. H., C. Dardick, L. E. Bartley, P. Cao, J. Phetsom, P. Canlas, Y. S. Seo, M. Shultz, S. Ouyang, Q. Yuan, B. C. Frank, E. Ly, L. Zheng, Y. Jia, A. P. Hsia, K. An, H. H. Chou, D. Rocke, G. C. Lee, P. S. Schnable, G. An, C. R. Buell and P. C. Ronald (2008). "Refinement of light-responsive transcript lists using rice oligonucleotide arrays: evaluation of gene-redundancy." PLoS ONE 3(10): e3337.

Kane, N. C., N. Gill, M. J. King, J. E. Bowers, H. Berges, J. Gouzy, E. Bachlava, N. B. Langlade, Z. Lai, M. Stewart, J. M. Burke, P. Vincourt, S. J. Knapp and L. H. Rieserberg (2011). "Progress towards a reference genome for sunflower." Botany 89: 429-437.

Khanna-Chopra, R. (2011). "Leaf senescence and abiotic stresses share reactive oxygen species-mediated chloroplast degradation." Protoplasma.

Kim, J. H., P. O. Lim and H. G. Nam (2007). Molecular regulation of leaf senescence. "Senescence Process in Plants". S. Gan. Ithaca, Blackwell Publishing.

Kim, J. H., H. R. Woo, J. Kim, P. Ok Lim, I. C. Lee, S. H. Choi, D. E. Hwang and H. Gil Nam (2009). "Trifurcate Feed-Forward Regulation of Age-Dependent Cell Death Involving miR164 in Arabidopsis." Science 323(5917): 1053-1057.

Kim, J. I., A. S. Murphy, D. Baek, S. W. Lee, D. J. Yun, R. A. Bressan and M. L. Narasimhan (2011). "YUCCA6 over-expression demonstrates auxin function in delaying leaf senescence in Arabidopsis thaliana." J Exp Bot 62(11): 3981-3992.

Kusnierczyk, A., P. Winge, T. S. Jorstad, J. Troczynska, J. T. Rossiter and A. M. Bones (2008). "Towards global understanding of plant defence against aphids--timing and dynamics of early Arabidopsis defence responses to cabbage aphid (Brevicoryne brassicae) attack." Plant Cell Environ 31(8): 1097-1115.

Lai, Z., B. L. Gross, Y. Zou, J. Andrews and L. H. Rieseberg (2006). "Microarray analysis reveals differential gene expression in hybrid sunflower species." Mol Ecol 15(5): 1213-1227.

Larkin, J. E., B. C. Franc, H. Gavras, R. Sultana and J. Quackenbush (2005). "Independence and reproducibility across microarray platforms." Nat. Methods 2(5): 337-344.

Li, X., H.-I. Chiang, J. Zhu, S. E. Dowd and H. Zhou (2008). "Characterization of a newly developed chicken 44K Agilent microarray." BMC Genomics 9:60.

Lim, P., H. Kim and H. Nam (2007). "Leaf Senescence." Annual Rev. Plant Biol. 58: 115-136.

Lim, P. O., H. R. Woo and H. G. Nam (2003). "Molecular genetics of leaf senescence in Arabidopsis." Trends in Plant Science 8: 272-278.

Lin, J.-F. and S.-H. Wu (2004). "Molecular events in senescing Arabidopsis leaves." The Plant Journal 39(4): 612-628.

Lohman, K. N., S. Gan, M. C. John and R. M. Amasino (1994). "Molecular analysis of natural leaf senescence in Arabidopsis thaliana." Physiol Plant 92(2): 322-328.

Manavella, P. A., A. L. Arce, C. A. Dezar, F. Bitton, J. P. Renou, M. Crespi and R. L. Chan (2006). "Cross-talk between ethylene and drought signalling pathways is mediated by the sunflower Hahb-4 transcription factor." Plant J 48(1): 125-137.

Manavella, P. A., C. A. Dezar, G. Bonaventure, I. T. Baldwin and R. L. Chan (2008). "HAHB4, a sunflower HD-Zip protein, integrates signals from the jasmonic acid 
and ethylene pathways during wounding and biotic stress responses." The Plant Journal 56(3): 376-388.

Martinez-Godoy, M. A., N. Mauri, J. Juarez, M. Carmen Marques, J. Santiago, J. Forment and J. Gadea (2008). "A genome-wide 20K citrus microarray for gene expression analysis." BMC Genomics 9(318).

Martinez, D. E., C. G. Bartoli, V. Grbic and J. J. Guiamet (2007). "Vacuolar cysteine proteases of wheat (Triticum aestivum L.) are common to leaf senescence induced by different factors." J Exp Bot 58(5): 1099-1107.

Mascarrell-Creus, A., J. Cañizares, J. Vilarrasa-Blasi, S. Mora-Garcia, J. Blanca, D. GonzalezIbeas, M. Saladié, C. Roig, W. Deleu, B. Picó-Silvent, N. López-Bigas, M. A. Aranda, J. Garcia-Mas, F. Nuez, P. Puigdomènech and A. Caño-Delgado (2009). "An oligobased microarray offers novel transcriptomic approaches for the analysis of pathogen resistance and fruit quality traits in melon (Cucumis melo L.)." BMC Genomics 10(467).

Moschen, S. (2009). "Identificación y caracterización de genes asociados a la senescencia tempana en girasol". Tesis de Grado. Lic. en Genética.

Moschen, S., P. Fernandez, N. Paniego and R. A. Heinz (2010). "'Análisis de los perfiles de expresión de factores de transcripción NAC asociados a la senescencia foliar en girasol (Helianthus annuus L.)"." Reunión Argentina de Fisiología Vegetal.

Mungall, C. J., D. B. Emmert and T. F. Consortium (2007). "A Chado case study: an ontologybased modular schema for representing genome-associated biological information." Bioinformatics 23(13): i337-i346.

"National Center for Biotechnology Information (NCBI)." http://www.ncbi.nlm.nih.gov/.

Nazar, N. R., P. Chen, D. Dean and J. Robb (2010). "DNA Chip Analysis in Diverse Organisms with Unsequenced Genomes." Mol. Biotechnol 44: 8-13.

Noodén, L. and J. Penny (2001). "Correlative controls of senescence and plant death in Arabidopsis thaliana (Brassicaceae)." J. Exp. Bot. 52: 2151-2159.

Noodén, L. D. (1988). The phenomena of senescence and aging. . Senescence and Aging in Plants. A. C. L. L.D. Noodén. San Diego, Academic: 1-50.

Noodén, L. D., J. J. Guiamet and J. Isaac (1997). "Senescence mechanisms." Physiologia plantarum 101: 746-753.

Noodén, L. D. and A. C. Leopold (1987). "Phytohormones and the endogenous regulation of senescence and abscission". "Phytohormones and related compounds: A comprehensive treatise". Amsterdam, Elsevier: 329-370.

Nooden, L. D. and Z. C. Leopold (1988). "The phenomena of senescence and aging. In "Senescence and aging in plants"." Academic Press. San Diego CA, USA: 1-50.

Nuruzzaman, M., R. Manimekalai, A. M. Sharoni, K. Satoh, H. Kondoh, H. Ooka and S. Kikuchi (2010). "Genome-wide analysis of NAC transcription factor family in rice." Gene 465(1-2): 30-44.

Olsen, A. N., H. A. Ernst, L. L. Leggio and K. Skriver (2005). "NAC transcription factors: structurally distinct, functionally diverse." Trends Plant Sci 10(2): 79-87.

Ooka, H., K. Satoh, K. Doi, T. Nagata, Y. Otomo, K. Murakami, K. Matsubara, N. Osato, J. Kawai, P. Carninci, Y. Hayashizaki, K. Suzuki, K. Kojima, Y. Takahara, K. Yamamoto and S. Kikuchi (2003). "Comprehensive analysis of NAC family genes in Oryza sativa and Arabidopsis thaliana." DNA Res 10(6): 239-247. 
Ophir, R., R. Eshed, R. Harel-Beja, G. Tzuri, V. Portnoy, Y. Burger, S. Uliel, N. Katzir and A. Sherman (2010). "High-throughput marker discovery in melon using a selfdesigned oligo microarray." BMC Genomics 11: 269.

Otegui, M. S., Y. S. Noh, D. E. Martinez, M. G. Vila Petroff, L. A. Staehelin, R. M. Amasino and J. J. Guiamet (2005). "Senescence-associated vacuoles with intense proteolytic activity develop in leaves of Arabidopsis and soybean." Plant J 41(6): 831-844.

Ott, H., C. Schroder, M. Raulf-Heimsoth, V. Mahler, C. Ocklenburg, H. F. Merk and J. M. Baron (2010). "Microarrays of recombinant Hevea brasiliensis proteins: a novel tool for the component-resolved diagnosis of natural rubber latex allergy." J Investig Allergol Clin Immunol 20(2): 129-138.

Paniego, N., R. Heinz, P. Fernandez, P. Talia, V. Nishinakamasu and H. Hopp (2007). Sunflower. Genome Mapping and Molecular Breeding in Plants. C. Kole. Berlin Heidelberg, Springer-Verlag. 2: 153-177.

Park, J. H., S. A. Oh, Y. H. Kim, H. R. Woo and H. G. Nam (1998). "Differential expression of senescence-associated mRNAs during leaf senescence induced by different senescence-inducing factors in Arabidopsis." Plant Mol Biol 37(3): 445-454.

Peluffo, L., V. Lia, C. Troglia, C. Maringolo, N. Paniego, R. A. Heinz and F. Carrari (2010). "Metabolic profiles of sunflower genotypes with contrasting response to Sclerotinia sclerotiorum infection." Phytochemistry.

Pic, E., B. Teyssandier de la Serve, F. Tardieu and O. Turc (2002). "Leaf senescence induced by mild water deficit follows the same sequence of macroscopic, biochemical, and molecular events as monocarpic senescence in pea." Plant Physiology 128: 236-246.

Rivero, R. M., M. Kojima, A. Gepstein, H. Sakakibara, R. Mittler, S. Gepstein and E. Blumwald (2007). "Delayed leaf senescence induces extreme drought tolerance in a flowering plant." Proc Natl Acad Sci U S A 104(49): 19631-19636.

Roche, J., T. Hewezi, A. Bouniols and L. Gentzbittel (2007). "Transcriptional profiles of primary metabolism and signal transduction-related genes in response to water stress in field-grown sunflower genotypes using a thematic cDNA microarray." Planta DOI 10.1007/s00425-007-0508-0.

Sadras, V. O., L. Echarte and A. F. H. (2000). "Profiles of Leaf Senescence During Reproductive Growth of Sunflower and Maize." Annals of Botany 85(2): 187-195.

Sadras, V. O., M. Ferreiro, F. Gutheim and A. G. Kantolic (2000). Desarrollo fenológico y su respuesta a temperatura y fotoperíodo. Bases para el manejo del maíz, el girasol y la soja. I. B. F. d. C. A. UNMP: 29-60.

Sadras, V. O., F. Quiroz, L. Echarte, E. A. and P. V. R. (2000). "Effect of Verticillium dahliae on Photosynthesis, Leaf Expansion and Senescence of Field-grown Sunflower." Annals of Botany 86: 1007-1015.

Saeed, A., V. Sharov, J. White, J. Li, W. Liang, N. Bhagabati, J. Braisted, M. Klapa, T. Currier, M. Thiagarajan, A. Sturn, M. Snuffin, A. Rezantsev, D. Popov, A. Ryltsov, E. Kostukovich, I. Borisovsky, Z. Liu, A. Vinsavich, V. Trush and J. Quackenbush (2003). "TM4: a free, open-source system for microarray data management and analysis." Biotechniques 34(2): 374-378.

Shahri, W. (2011). "Senescence: Concepts and Symptoms." Asian Journal of Plant Sciences 10(1): 24-28. 
Smykowski, A., P. Zimmermann and U. Zentgraf (2010). "G-Box Binding Factor1 Reduces CATALASE2 Expression and Regulates the Onset of Leaf Senescence in Arabidopsis." Plant Physiol 153(3): 1321-1331.

Smyth, G. (2004). "Linear models and empirical bayes methods for assessing differential expression in microarray experiments." Stat Appl Genet Mol Biol 3: Article3.

Song, S.-Y., Y. Chen, J. Chen, X.-Y. Dai and W.-H. Zhang (2011). "Physiological mechanisms underlying OsNAC5-dependent tolerance of rice plants to abiotic stress." Planta 234(2): 331-345.

Thomas, H. and I. Donnisson (2000). "Back from the brink: plant senescence and its reversibility." Symp Soc Exp Biol. 52: 149-162.

Thomas, H., L. Huang, M. Young and H. Ougham (2009). "Evolution of plant senescence." BMC Evol Biol 9: 163.

Trick, M., F. Cheung, N. Drou, F. Fraser, E. K. Lobenhofer, P. Hurban, A. Magusin, C. D. Town and I. Bancroft (2009). "A newly-developed community microarray resource for transcriptome profiling in Brassica species enables the confirmation of Brassicaspecific expressed sequences." BMC Plant Biology 9(50).

Uauy, C., A. Distelfeld, T. Fahima, A. Blechl and J. Dubcovsky (2006). "A NAC Gene regulating senescence improves grain protein, zinc, and iron content in wheat." Science 314(5803): 1298-1301.

Ülker, B. and E. I. Somssich (2004). "WRKY transcription factors: from DNA binding towards biological function." Current Opinion in Plant Biology 7: 491-498.

Weaver, M. and R. Amasino (2001). "Senescence is induced in individually darkened Arabidopsis leaves, but inhibited in whole darkened plants." Plant Physiology 127: 876-886.

Wingler, A., S. Purdy, J. A. MacLean and N. Pourtau (2006). "The role of sugars in integrating environmental signals during the regulation of leaf senescence." Journal of Experimental Botany 57(2): 391-399.

Woo, H. R., J. H. Kim, J. Kim, U. Lee, I. J. Song, H. Y. Lee, H. G. Nam and P. O. Lim (2010). "The RAV1 transcription factor positively regulates leaf senescence in Arabidopsis." J Exp Bot 61(14): 3947-3957.

Zavaleta-Mancera, H. A., B. J. Thomas, H. Thomas and I. M. Scott (1999a). "Regreening of senescent Nicotiana leaves: II Redifferentiation of plastids." Journal of Experimental Botany 50(340): 1683-1689.

Zavaleta-Mancera, H. A., B. J. Thomas, H. Thomas and I. M. Scott (1999b). "Regreening of senescent Nicotiana leaves: I Reappearance of NADPH-protochlorophyllide oxidoreductase and light-harvesting chlorophyll a/b-binding protein." Journal of Experimental Botany 50(340): 1677-1682.

Zhu, T. and X. Wang (2000). "Large-scale profiling of the Arabidopsis transcriptome." Plant Physiol 124(4): 1472-1476. 


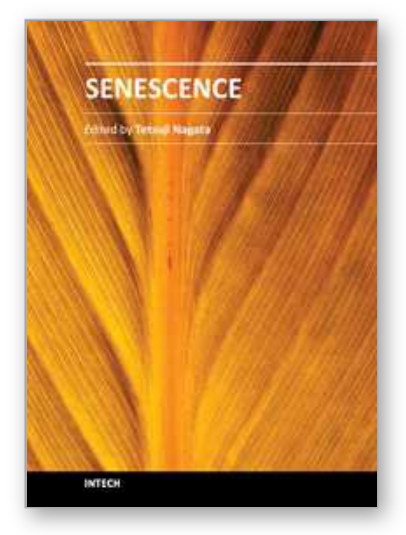

\author{
Senescence \\ Edited by Dr. Tetsuji Nagata
}

ISBN 978-953-51-0144-4

Hard cover, 850 pages

Publisher InTech

Published online 29, February, 2012

Published in print edition February, 2012

The book "Senescence" is aimed to describe all the phenomena related to aging and senescence of all forms of life on Earth, i.e. plants, animals and the human beings. The book contains 36 carefully reviewed chapters written by different authors, aiming to describe the aging and senescent changes of living creatures, i.e. plants and animals.

\title{
How to reference
}

In order to correctly reference this scholarly work, feel free to copy and paste the following:

Paula Fernandez, Sebastián Moschen, Norma Paniego and Ruth A. Heinz (2012). Functional Approaches to Study Leaf Senescence in Sunflower, Senescence, Dr. Tetsuji Nagata (Ed.), ISBN: 978-953-51-0144-4, InTech, Available from: http://www.intechopen.com/books/senescence/functional-approaches-to-study-leafsenescence-in-sunflower

\section{INTECH}

open science | open minds

\author{
InTech Europe \\ University Campus STeP Ri \\ Slavka Krautzeka 83/A \\ 51000 Rijeka, Croatia \\ Phone: +385 (51) 770447 \\ Fax: +385 (51) 686166 \\ www.intechopen.com
}

\author{
InTech China \\ Unit 405, Office Block, Hotel Equatorial Shanghai \\ No.65, Yan An Road (West), Shanghai, 200040, China \\ 中国上海市延安西路65号上海国际贵都大饭店办公楼405单元 \\ Phone: +86-21-62489820 \\ Fax: $+86-21-62489821$
}


(C) 2012 The Author(s). Licensee IntechOpen. This is an open access article distributed under the terms of the Creative Commons Attribution 3.0 License, which permits unrestricted use, distribution, and reproduction in any medium, provided the original work is properly cited. 